\title{
Assessment of the young adult hip joint using plain radiographs
}

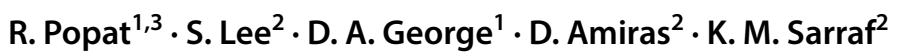

Received: 19 June 2019 / Accepted: 22 February 2020 / Published online: 3 March 2020

(c) The Author(s) 2020

\begin{abstract}
Radiographic examination remains the mainstay of the initial assessment of the young adult hip; however, common parameters are required to assist in the formation of accurate diagnoses and appropriate management plans. This paper aims to summarise the most important aspects of the assessment of plain radiographs performed on the young adult hip joint.
\end{abstract}

Keywords Assessment · Radiographs · Young adult · Hip joint

\section{Introduction}

An enhanced awareness of the presence of structural disorders of the hip, such as developmental dysplasia of the hip and femoroacetabular impingement (FAI), has fuelled an evolution in the assessment of patients with hip pain and enhanced our ability to diagnose patients, even in cases where there are mild structural abnormalities. Radiographic examination remains the mainstay of the initial assessment; however, common parameters are required to assist in the formation of accurate diagnoses and appropriate management plans including appropriate further imaging. This paper begins by describing the parameters that potentially impact the quality of antero-posterior (AP) and lateral radiographs of the hip, and the variations in lateral radiographs that can be used. This article aims to summarise the most important aspects of the assessment of plain radiographs performed on the young adult hip joint. Acetabular and femoral parameters that are assessed on plain radiographs are then described.

\section{R. Popat}

r.popat14@imperial.ac.uk

1 West Hertfordshire Hospitals NHS Trust, Watford General Hospital, Vicarage Road, Watford, Hertfordshire WD18 0HB, UK

2 Imperial College Healthcare NHS Trust, St Mary's Hospital, Praed Street, London W2 1NY, UK

3 Department of Trauma and Orthopaedic Surgery, West Hertfordshire Hospitals NHS Trust, Watford General Hospital, Vicarage Road, Watford, Hertfordshire WD18 0HB, UK

\section{Materials and methods}

A literature review into the assessment of hip pain in young adults was performed on Medline and Embase using the search terms 'hip pain', 'young adult' and 'plain radiographs'. Articles were then assessed for any references relating to assessment of hip pathology using plain radiographs with a view to summarising the key findings.

\section{Antero-posterior view}

A plain antero-posterior (AP) radiograph of the pelvis facilitates an assessment of each hip joint on an individual basis, as well as allowing for a comparison to be made to the contra-lateral hip joint. The AP pelvis X-ray can be performed in a supine position, with efforts made to control the pelvic tilt and rotation, enabling similar radiographs to be obtained in every patient. It can also be obtained in a weight-bearing manner, which may accentuate any arthritic changes, and give an indication of limb length discrepancy. When initially reviewing a plain radiograph of the pelvis, the radiograph should be assessed for adequacy. Images should allow for visualisation of the entire pelvis including the iliac crests, sacrum, sacroiliac joints, pubic and ischial rami, as well as the necks of the femora and the lesser and greater trochanters [1]. In addition, the following factors should be considered.

\section{Pelvis rotation}

An acceptable plain radiograph of the pelvis should be obtained with pelvis in a neutral position. In the absence of 
pathology, the two obturator foramen, ischial spines, greater and lesser trochanters and femoral heads should be symmetrical. The central sacral line and the tip of the coccyx should also align with the symphysis pubis (Fig. 1).

\section{Pelvic tilt}

A plain AP radiograph should have neutral tilt, which may require correction of lumbar lordosis. The distance between the sacro-coccygeal junction and the superior end of the symphysis should be between 2 and $3 \mathrm{~cm}$ in males and between 2 and $6 \mathrm{~cm}$ in females [2] (Fig. 1).

\section{Rotation of the lower limb}

Approximately $15^{\circ}$ of internal rotation of the hips, such that the greater and lesser trochanters are parallel to the floor, maximises the length of the femoral neck and enables a more accurate neck-shaft angle measurement [3]. Acquisition of the radiographic image with the patellae facing anteriorly can lead to over-estimation of the true neck-shaft angle [4].

\section{Film exposure}

The exposure of the radiograph is related the concentration of photons absorbed by the film, or digital detector, at the

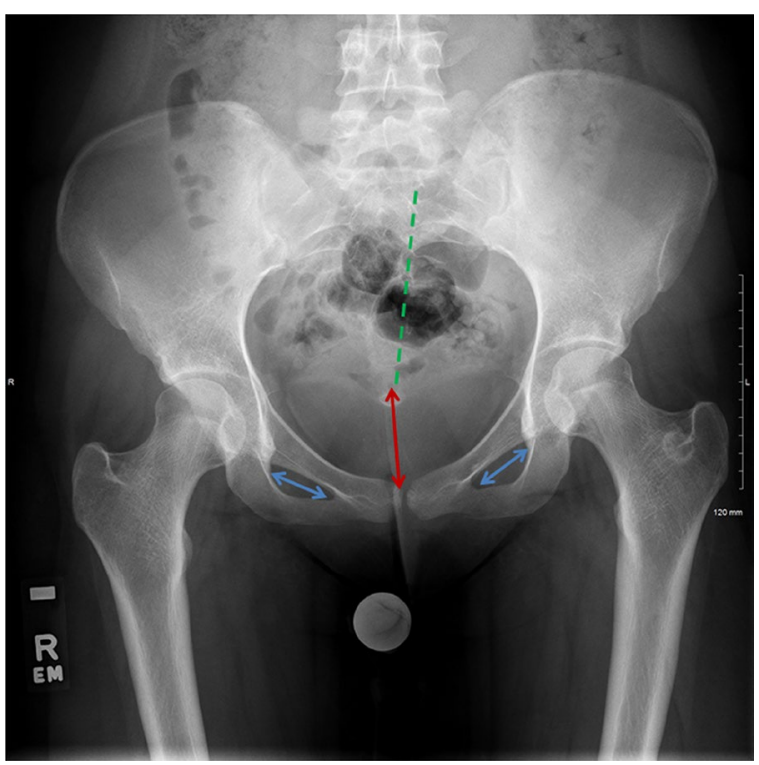

Fig. 1 AP radiograph pelvis depicting pelvic rotation and tilt. The central sacral line (green dotted line) should be aligned centrally from the tip of the coccyx to the symphysis pubis. The obturator foramina (blue arrows), ischial spine and trochanters should be symmetrical. In this case, there is a slight pelvic rotation. The distance between sacrococcygeal junction and the superior end of the symphysis (red arrow) is used to determine the pelvic tilt. A benign sclerotic ring is seen in the left trochanteric region time the radiograph was taken. Radiographic contrast is defined as the density difference between neighbouring areas on a plain radiograph $[5,6]$. Appropriate film exposure and contrast should enable delineation of the acetabular walls and the fat pads around the hip joint (gluteal, obturator and iliopsoas).

\section{Lateral radiographs}

A lateral radiograph of the hip can provide valuable information in the assessment of a young adult with hip pain. A variety of lateral views have been developed and are described.

\section{Cross-table lateral view}

This view is performed with the patient supine on an X-ray table and the symptomatic limb in approximately $15^{\circ}$ of internal rotation, and the image is taken at a $45^{\circ}$ angle to the symptomatic limb (Fig. 2). The contra-lateral limb is flexed beyond $80^{\circ}$ at the hip and knee joint. This view can demonstrate CAM deformities of the femoral neck and also gives clues about femoral version [7].

\section{False profile lateral view of the hip joint}

Taken with the patient in a standing position, it allows assessment of anterior acetabular coverage of the femoral head (Fig. 3) [8]. The anterior centre-edge angle can be measured, to investigate anterior subluxation during weight bearing. Only one hip can be studied at a time. This is

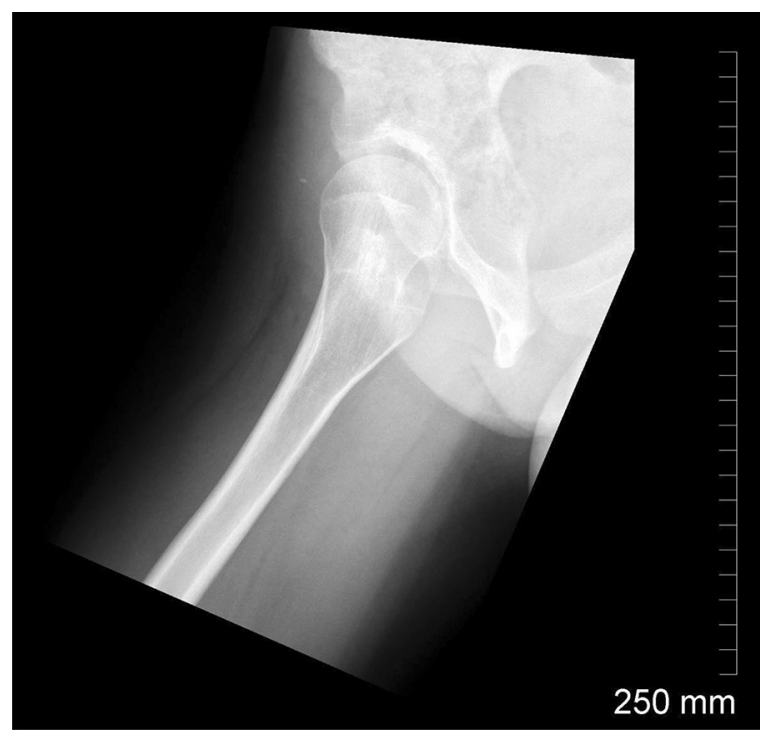

Fig. 2 Cross-table lateral view 


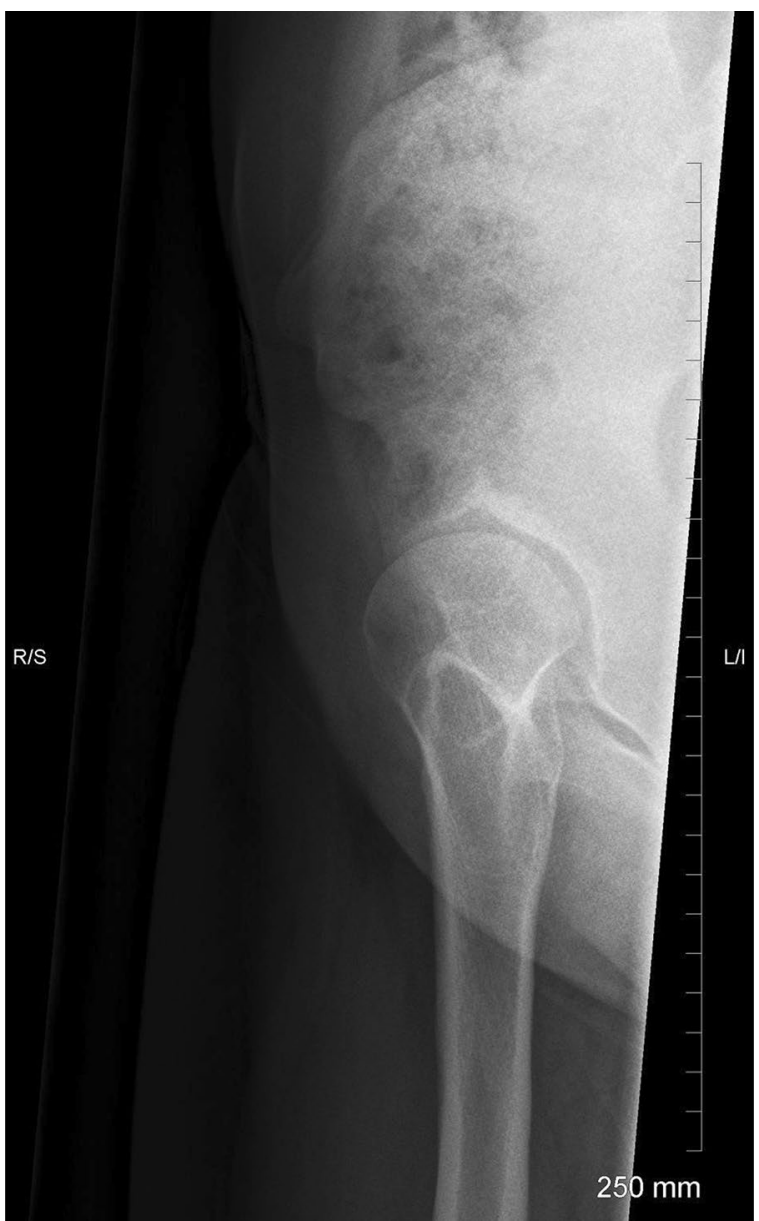

Fig. 3 False profile lateral view

especially useful when assessing a patient for peri-acetabular osteotomy (PAO).

\section{Frog lateral view of the hip joint}

It is performed with the patient supine on the X-ray table with the hip externally rotated and abducted to $45^{\circ}$, and the knee flexed approximately $30^{\circ}-40^{\circ}$ (Fig. 4) [9]. With both hips visible, it is possible to compare the range of motion between the two. Pelvic tilt will not be controlled; therefore, acetabular morphology is difficult to analyse. This is more commonly used in the paediatric skeletally immature population.

\section{${ }^{\circ}$ Dunn lateral view}

The patient's hips are flexed to $45^{\circ}$, in maximal abduction, with neutral rotation maintained providing a comparison image of both hips (Fig. 5) [10]. This view exhibits the anterograde superior head-neck junction well and allows

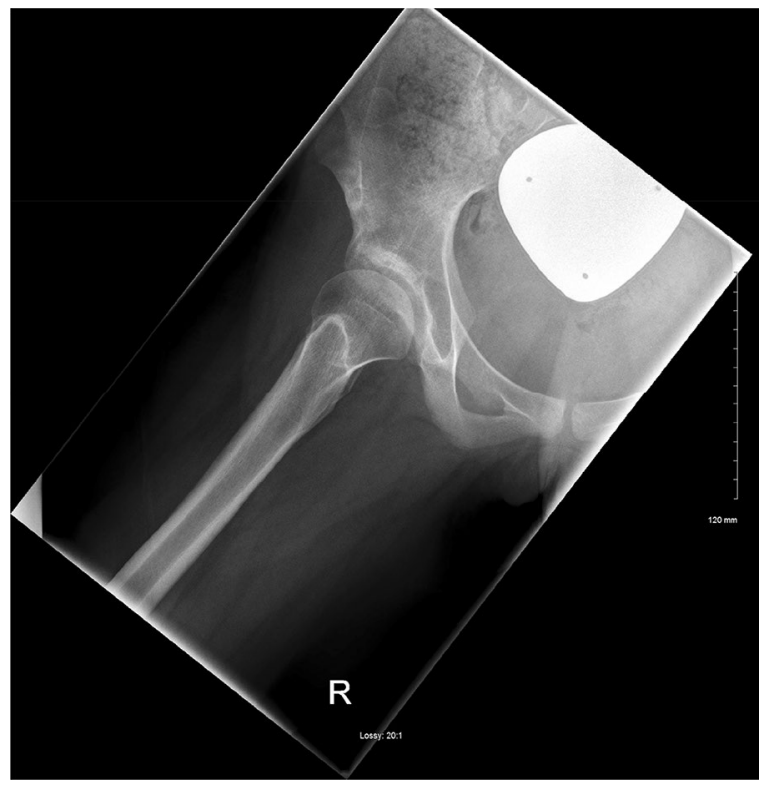

Fig. 4 Frog lateral view

femoral version to be estimated. It is also a helpful view for detections of signs of impingement.

\section{Modified Billing's lateral view}

A standard AP view of the hip is performed, but with $90^{\circ}$ of flexion, $65^{\circ}$ of abduction and neutral rotation of the hip.

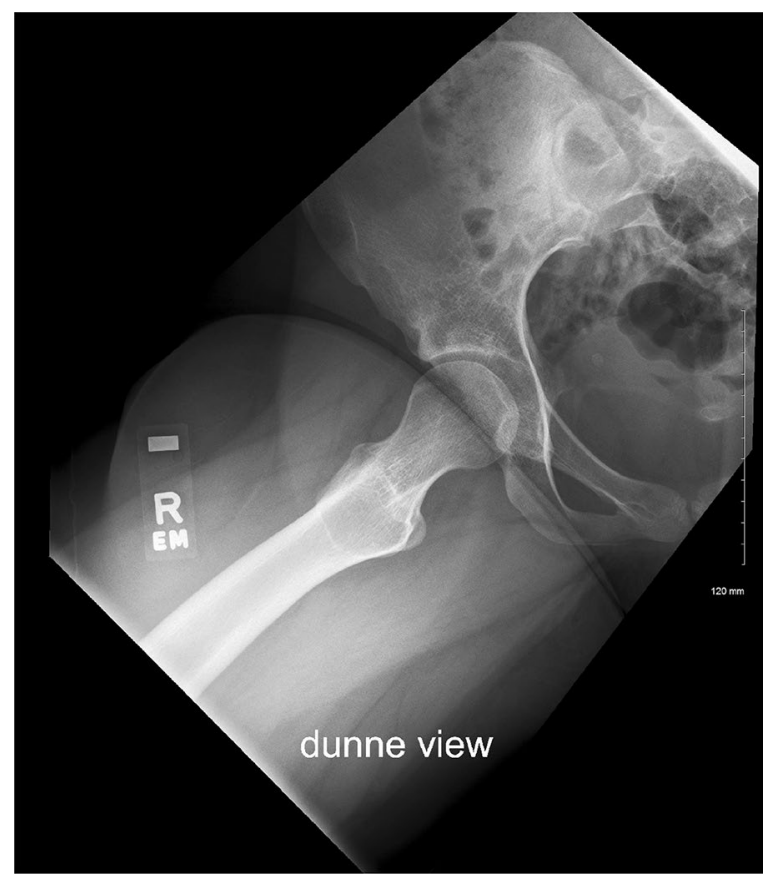

Fig. 5 Dunn lateral view 
The leg can be supported by a wedge when obtaining this view $[11,12]$.

\section{Acetabular parameters}

\section{Teardrop}

This radiographic teardrop represents the innominate bone at the inferior end of the acetabulum [13, 14]. The teardrop is normally U-shaped and made up of a medial border (continuous with the ilioischial line) and a lateral border (continuous with the floor of the acetabulum). A wider teardrop sign can typically represent acetabular dysplasia or joint effusion $[15,16]$, whereas a narrowing, crossover of the medial and lateral borders can indicate an acetabulum that is deeper than normal, resulting in coxa profunda (Fig. 6).

\section{Sourcil}

This delineates the weight-bearing portion of the acetabular dome [17]. In a normal femoroacetabular joint, the Sourcil covers approximately $80 \%$ of the femoral head (difficult to assess in the presence of a CAM deformity). Acetabular inclination can be assessed on an AP Pelvic view using the Sourcil or Tönnis angle [18] (Fig. 7). These measurements can indicate dysplasia of the acetabular dome, whether a patient is at a higher risk of instability, or demonstrates risk factors for PINCER impingement.

The Tönnis angle is determined by drawing three lines:

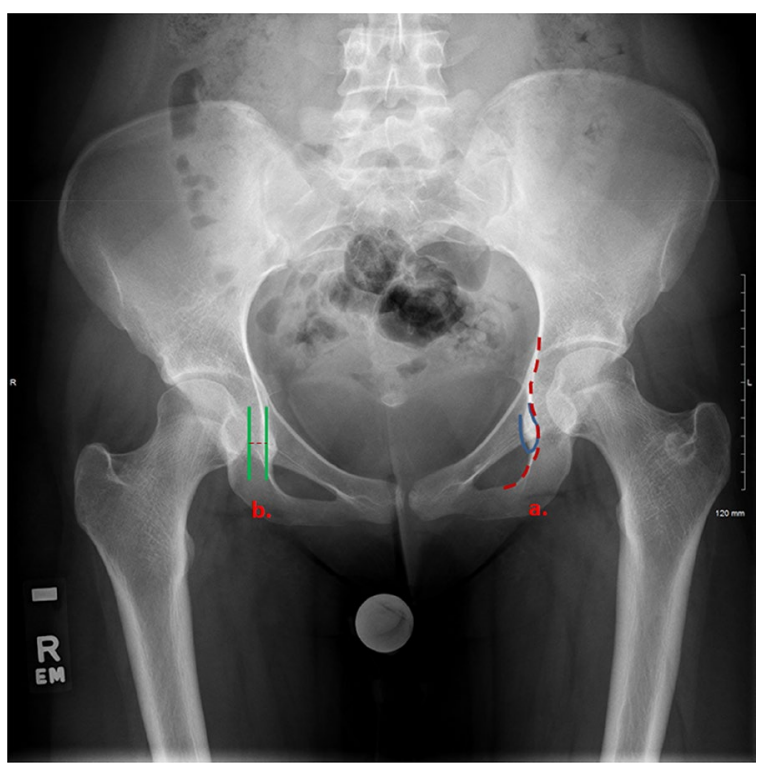

Fig. 6 a Teardrop sign. The U-shaped (blue line) teardrop consists of ilioischial line (red dotted arrow) and floor of the acetabulum. b Teardrop distance

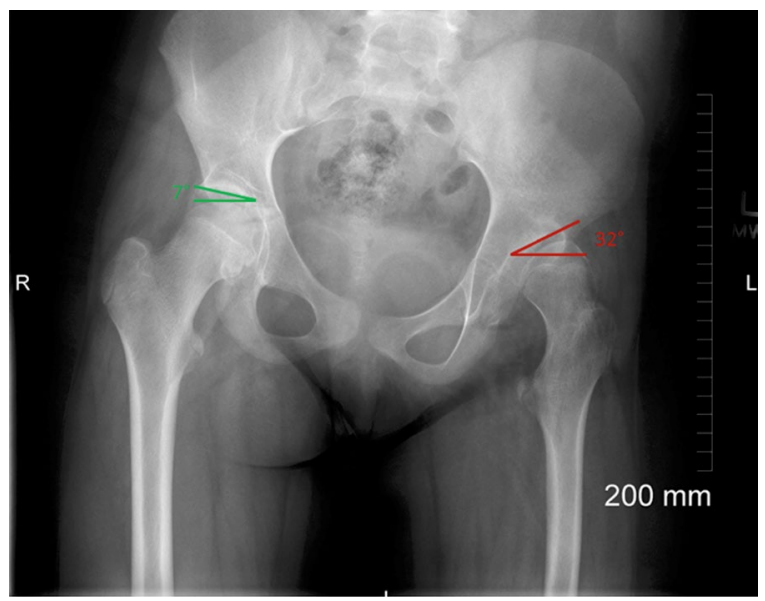

Fig. 7 Sourcil (Tönnis) angle. The right hip (green angle) represents normal Sourcil angle, whereas the left hip (red angle) represents increased Sourcil angle. Lateral translation of the femoral head is clearly visible in keeping with hip dysplasia

1. A horizontal line connecting the base of the acetabular teardrops

2. A horizontal line parallel to line 1, running through the most inferior point of the sclerotic acetabular Sourcil

3. A line extending from most inferior to the lateral margin of the acetabular Sourcil.

The Sourcil, or Tönnis angle, is formed by the intersection of lines 2 and 3 . This angle determines the joint reaction force that is transmitted along the primary compression trabecula of the femur perpendicular to the slope of the Sourcil.

An increased Tönnis angle $\left(>10^{\circ}\right)$ increases the risk of lateral translation of the femoral head in relation to the acetabulum, which is initially contained by the labrum and joint capsule. Lateral subluxation of the head results when the labrum eventually fails. A downsloping Sourcil leads to medial translation of the femoral head and medial osteoarthritis or PINCER impingement.

\section{Acetabular version}

Normal acetabulum version is approximately $20^{\circ}$ of anteversion, and although difficult to accurately delineate on X-ray, it is best assessed on an AP view of the pelvis [19]. All acetabula can be labelled as retroverted or anteverted on the basis of the presence or absence of a crossover sign. The posterior wall of the acetabulum is relatively vertical and extends to the ischium, with the anterior wall being more horizontal and extending down towards the pubis. In an anteverted acetabulum, the anterior and posterior walls are in contact at the lateral edge of the Sourcil, but do not cross over more inferiorly (Fig. 8). 


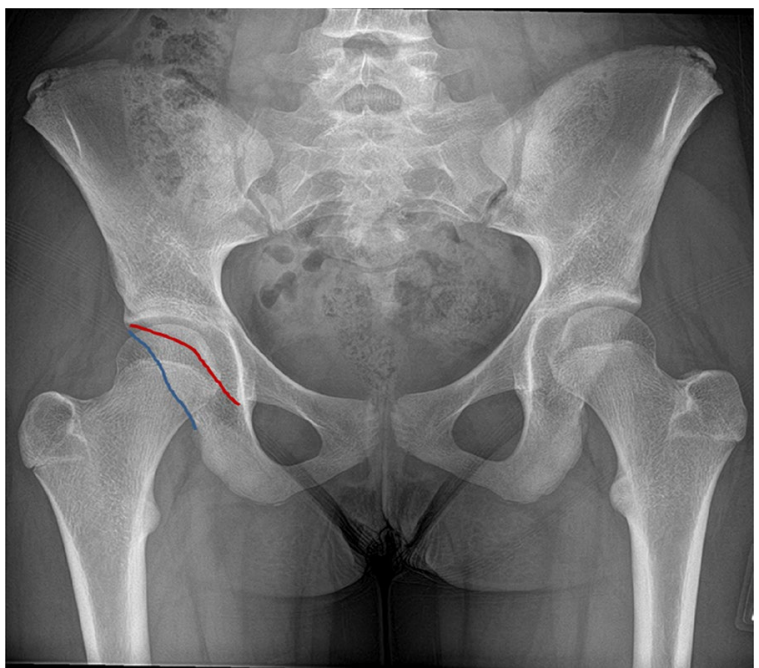

Fig. 8 Anterior and posterior acetabular walls do not crossover and are only in contact at the lateral edge of the Sourcil suggestive of an anteverted acetabulum

The acetabulum is considered to be retroverted if the line representing the anterior aspect of the acetabular rim does cross the line representing the posterior aspect of the acetabular rim. This can be a difficult determination to make, requiring careful assessment of the film quality, needless to say CT scan is the more accurate method to demonstrate acetabular version (Fig. 9).

The line of the anterior wall of the acetabulum typically covers the femoral head to a lesser extent than the line of the posterior acetabular wall, which routinely passes through the centre of the femoral head. Passage of the posterior acetabular wall medial to the femoral head indicates that posterior coverage is deficient, whereas passage of the posterior acetabular wall lateral to the femoral head would indicate excessive posterior coverage [20].

\section{Lateral centre-edge (LCE) angle of Wiberg}

LCE is another measurement of acetabular coverage of the femoral head. It is measured on the AP radiograph by forming an angle between a line through the centre of the femoral head, placed perpendicular to the pelvic tear drop line, and a second line placed along the lateral margin of the acetabulum. An angle between $25^{\circ}$ and $40^{\circ}$ is regarded as normal with $20^{\circ}-25^{\circ}$ being borderline. Ogata's angle is a variant of the LCE angle where a line is drawn along the lateral edge of the sclerotic rim seen at the acetabular roof (Sourcil) instead of the lateral most edge of the acetabulum. Ogata et al. [20] have concluded that these are not the same in patients with developmental dysplasia of the hip (DDH) and concurrent acetabular retroversion. Placing a line along the lateral most edge of the acetabulum would likely lead to over-estimation of LCE angle in this patient group [21].

\section{Anterior centre-edge (ACE) angle}

It is used to evaluate the anterior coverage of the acetabulum on false profile view as previously mentioned. A line is placed at the centre of the femoral head, which is parallel to the femoral neck on false profile view. A second line is placed along the anterior acetabular rim forming an angle. A normal angle would be between $20^{\circ}$ and $40^{\circ}$ with lesser and greater measurements representing anterior acetabular under and over coverage, respectively [22].
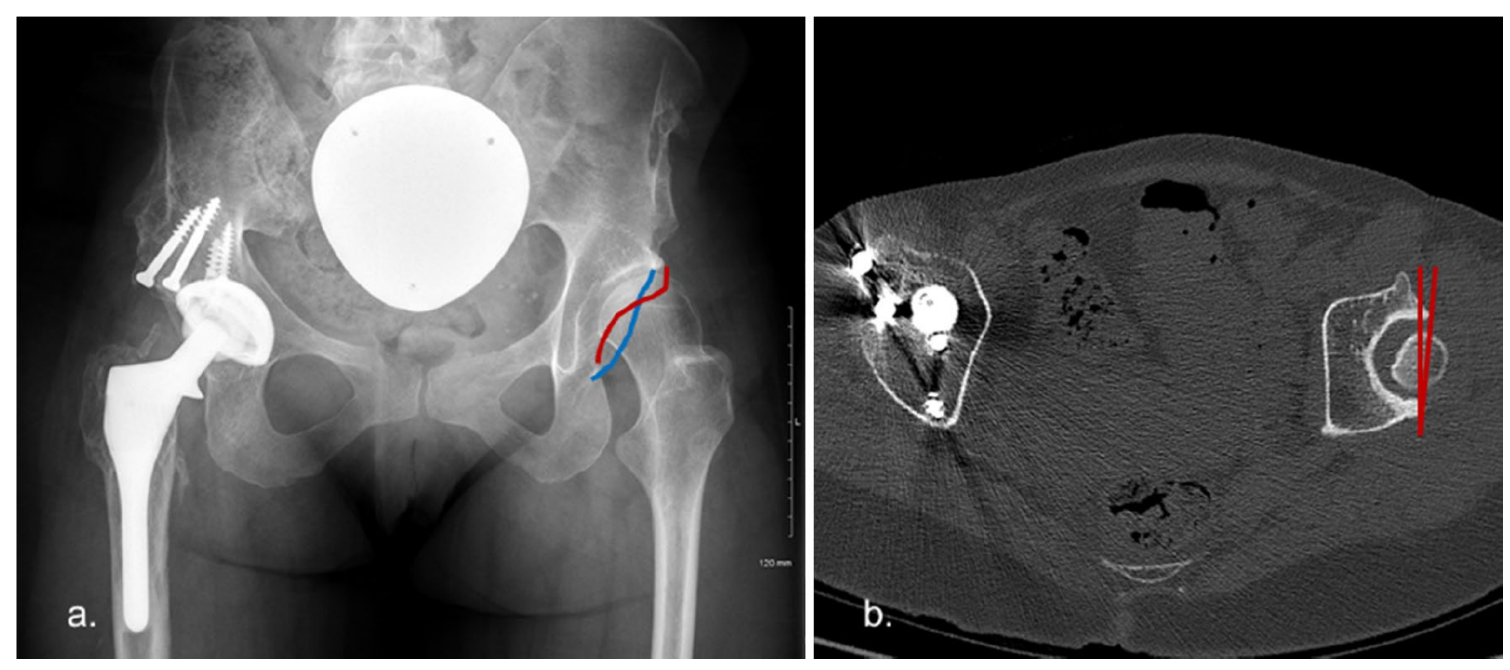

Fig. 9 a AP radiograph pelvis. There is a crossover of the anterior and posterior walls of the left acetabulum, which represents acetabular retroversion. b CT axial image of the same patient which demonstrates left acetabular retroversion 


\section{Acetabular quotient}

This ratio is dependent on the acetabular depth and acetabular width. The width of the acetabulum is measured between the inferior margin of the teardrop and the lateral margin of the acetabulum. A perpendicular line is placed from the midpoint of the acetabular width measurement to the centre of the acetabular dome. The measurement is performed on AP radiograph and calculated via acetabular depth/acetabular width $\times 1000$. A value of less than 250 would be regarded as representing hip dysplasia [22].

Other radiographic signs to be aware of include the presence of subchondral cysts, which develop from rim loading and after advanced damage from CAM impingement. Osteophyte formation develops from the ossified labrum around the rim of the acetabulum in pincer impingement.

\section{Femoral parameters}

The femoral head has a concave and largely symmetrical outline. Flattening of the femoral head or overgrowth of the epiphysis on to the femoral neck can produce a misshapen CAM-type impingement and result in incongruity between the femoral head and acetabulum.

\section{Sagging rope sign}

On a AP view of the pelvis, the sagging rope sign identifies abnormal extension of the femoral head on to the femoral neck [23]. The extent of the deformity can be assessed on a cross-table lateral, a frog lateral or a $45^{\circ}$ Dunn view, with Mose circles [24] utilised to objectively assess the sphericity of the femoral head. Clohisy et al. [3] state that if the femoral epiphysis extends beyond the margin of a reference circle by more than $2 \mathrm{~mm}$, the femoral head is considered aspherical.

Extension of the physeal scar to the superior aspect of the femoral neck on an AP pelvis is typical of a CAM deformity of the femoral head (Fig. 10).

\section{Fovea centralis}

The fovea is another sign that is visible on an AP pelvis radiograph. This represents the attachment of the ligamentum teres and represents somewhat of a watershed point. The articular cartilage inferior to the fovea is thinner in comparison with the cartilage superior to the fovea. The fovea typically manifests on a normal plain radiograph as a depression that is located medially and inferiorly, such that

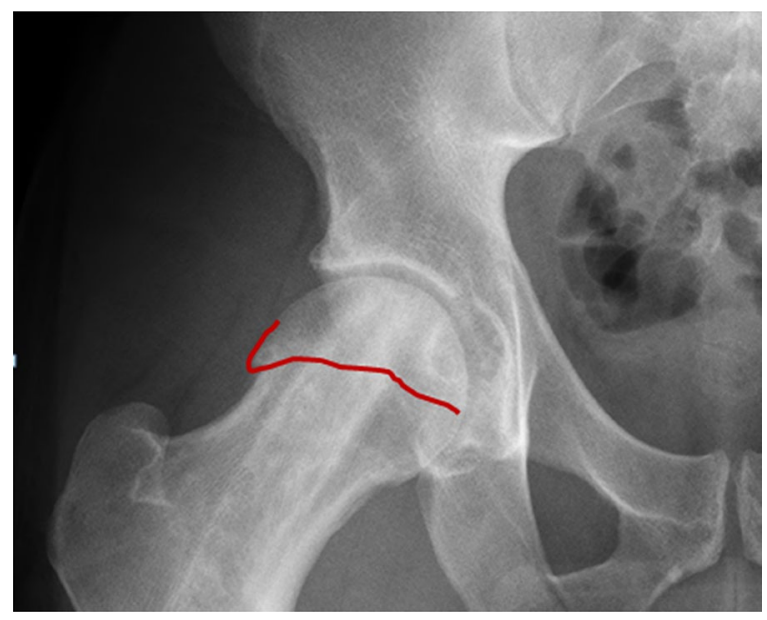

Fig. 10 Red line represents a physeal scar which is seen to extend along the lateral margin of the femoral head-neck creating a CAMtype deformity

it does not come into contact with the Sourcil. A fovea that is superiorly placed (coming into contact with the Sourcil) is abnormal and is called a Fovea alta (Fig. 11) [25].

The femoral neck provides adequate clearance around the femoral head to allow a normal range of movement, but also provides a lever arm that allows the hip abductors to function normally. A number of variables can be identified in relation to the femoral neck on plain radiographs [26].

\section{Neck-shaft angle}

The angle between the femoral shaft axis and the femoral neck axis is term the neck-shaft angle and is usually $125^{\circ}-130^{\circ}$ [27]. This angle can be calculated on an AP radiograph of the pelvis with the hips internally rotated approximately $15^{\circ}$ (or until the femoral neck is horizontal to the floor). External rotation or excessive internal rotation of the femur will increase the apparent neck-shaft angle. Coxa valga is a deformity of the hip where the angle formed between the femoral neck and femoral shaft (neck-shaft angle) is increased, usually above $135^{\circ}$. Coxa valga can lead to increased joint reaction forces within the hip. Coxa vara is a deformity where the neck-shaft angle is less than $120^{\circ}$ (Fig. 12). Coxa breva describes deformity where the femoral neck is excessively short. Coxa vara and coxa breva have the effect of reducing the resting length of the abductor muscles, which can manifest by limiting abductor function, resulting in a Trendelenburg gait [28].

\section{Femoral version}

It is described as the angular difference between the femoral neck-horizontal angle and the trans-condylar horizontal angle of the knee. When the femoral condyle is internally 


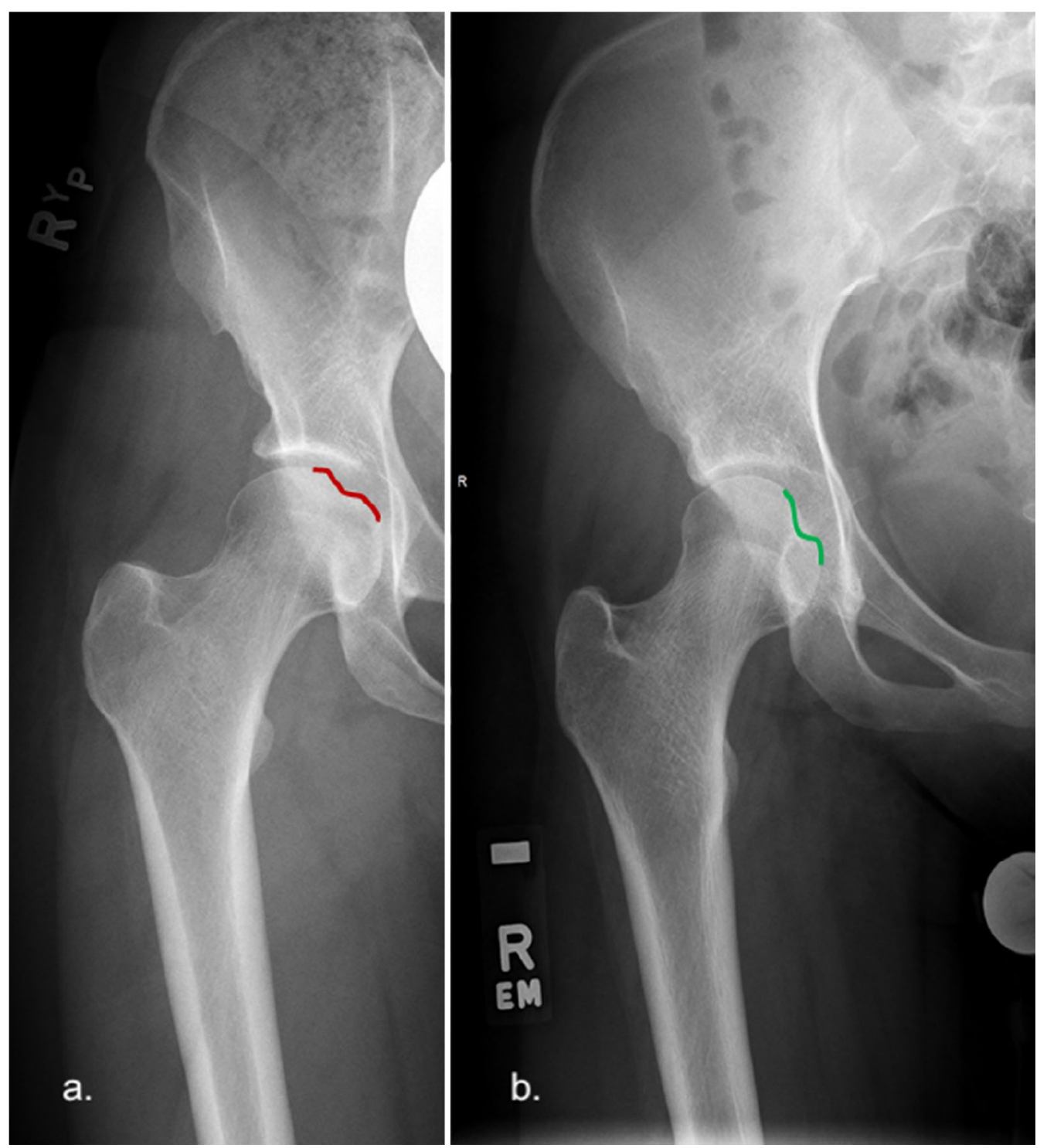

Fig. 11 a Fovea on the right (red depression) is in contact with the Sourcil and represents Fovea alta. b Fovea on the left (green depression) is located medially and inferiorly and is therefore normally situated

rotated, the trans-condylar horizontal angle is added to the neck-horizontal angle to calculate the degree of anteversion (Fig. 13). Normal version is approximately $5^{\circ}-20^{\circ}$ of anteversion [29].

\section{Femoral offset}

It is measured as the perpendicular distance from the axis of the shaft of the femur to the centre of rotation of the femoral head and reflects the displacement of the femur from the pelvis. Femoral offset influences various factors associated with hip function including abductor muscle function and impingement [30].
A narrow femoral neck around a larger femoral head is desirable to maintain a good range of movement. Movement within the hip joint will be permitted until the acetabular labrum interacts with the femoral neck at its maximal concavity. The anterior femoral neck is most commonly the area of impingement, and this occurs when the abnormal head-neck offset [31] is more superior on the anterior aspect of the neck.

The head-neck offset ratio can be calculated using a lateral radiograph of the hip joint. Three lines need to be drawn:

1. A line through the long axis of the femoral neck 


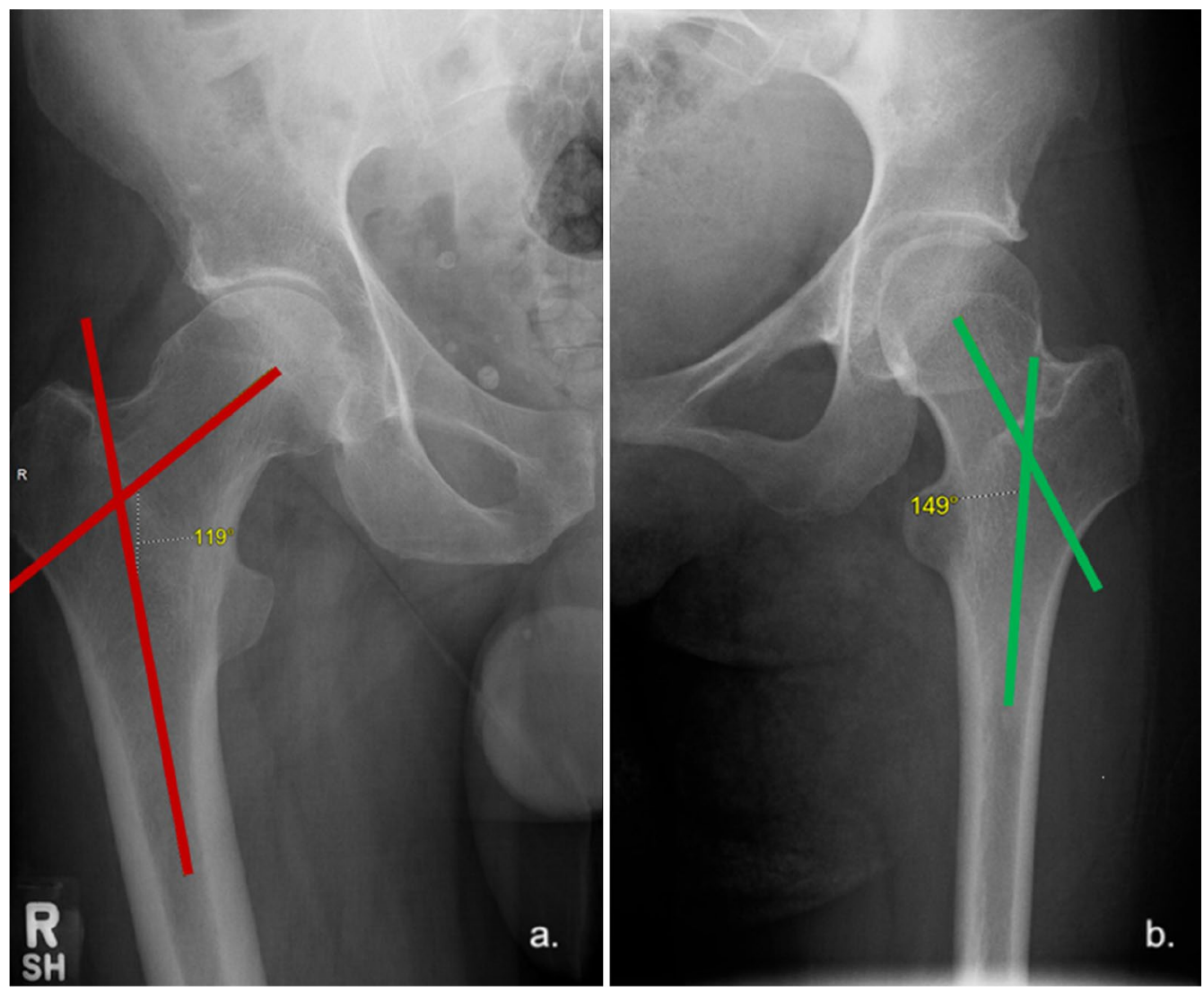

Fig. 12 Neck-shaft angle. a Right hip (red angle) measures $119^{\circ}$ and therefore is regarded as coxa vara. b Left hip (green angle) measures $149^{\circ}$ and therefore represents coxa valga

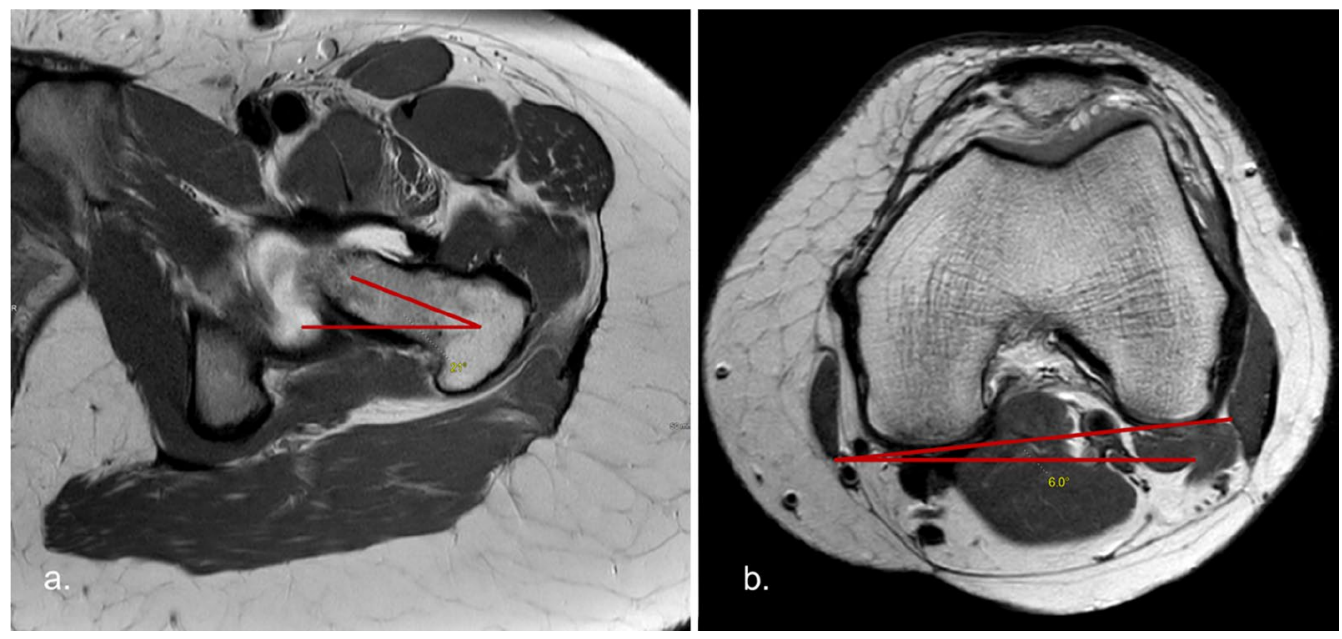

Fig. 13 MR axial proton density (PD) sequences. a Level of the left femoral neck demonstrating femoral neck-horizontal angle. b Trans-condylar axis of the left knee demonstrating trans-condylar horizontal angle

2. A line parallel to line 1 through the most anterior aspect of the femoral neck

3. A line parallel to line 2 through the most anterior aspect of the femoral head.
The distance between lines 2 and 3 is measured. This value is then divided by the diameter of the femoral head [32], with a ratio $<0.17$ indicating the presence of a cam deformity. 


\section{Alpha angle}

The alpha angle was classically described for use with crosssectional imaging (ultrasound, magnetic resonance imaging or computed tomography scans); however, a value can be extrapolated using a lateral radiograph of the hip joint (Fig. 14) [33].

Two lines are required to measure the alpha angle:

1. A line from the centre of the femoral neck to the centre of the femoral head.

2. A line from the centre of the femoral head to the point where the prominence starts (i.e. the point on the anterolateral aspect of the head-neck junction where the radius of the femoral head first becomes greater than the radius of the femoral head found more centrally in the acetabulum). Values of $>57^{\circ}$ are suggestive of a head-neck offset deformity.

\section{Congruity of the hip}

The articular surfaces of the femoral head and acetabulum are usually parallel to one another. Congruity of the hip can be assessed using all of the radiographic views described previously. The hip joint can be classified as congruous or incongruous based on the subjective assessment of the degree of conformity between the femoral head and the acetabulum.

\section{Hip centre}

This can be assessed on an AP radiograph of the pelvis and can be classified as lateralised or not lateralised. This

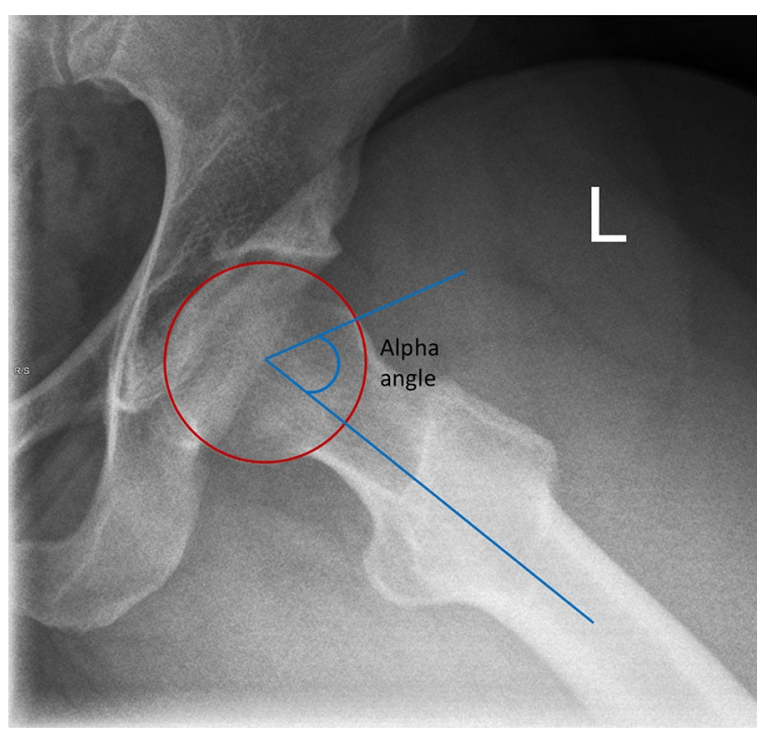

Fig. 14 Alpha angle on lateral plain radiograph of left hip

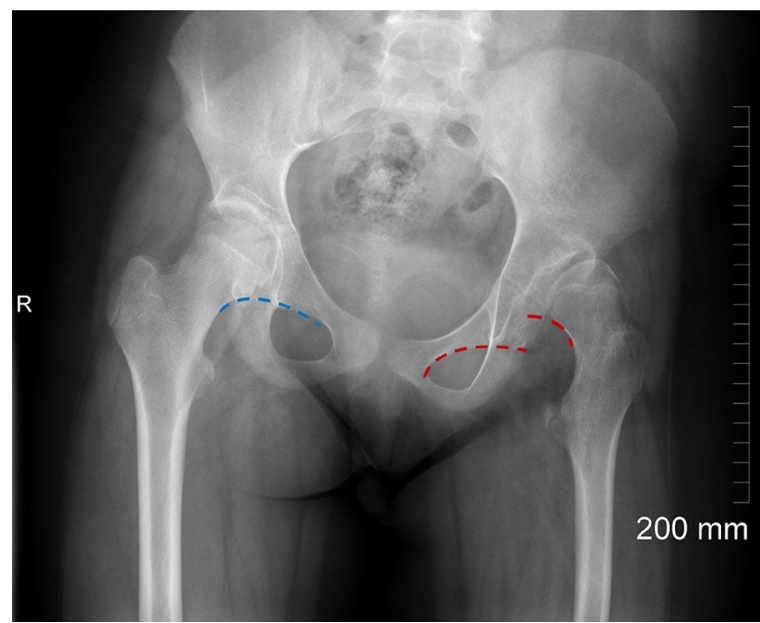

Fig. 15 Right hip (blue dotted line) demonstrates preserved Shenton's line. The left hip (red dotted line) represents 'breaking' of Shenton's line resulting from superior and lateral subluxation of the dysplastic hip joint

assessment is based on the position of the medial aspect of the femoral head in relation to the ilioischial line. A value greater than $10 \mathrm{~mm}$ denotes that the hip centre has been lateralised.

\section{Shenton's line}

This is an imaginary line drawn along the infero-medial aspect of the femoral neck and along the inferior border of the ipsilateral superior pubic ramus [34]. Superior and lateral subluxation of the femoral head will manifest on an AP radiograph of the pelvis by 'breaking' Shenton's line (Fig. 15). Excessive external rotation of a normal hip can also break Shenton's line without subluxation of the femoral head.

\section{Conclusion}

An approach to the assessment of plain radiographs in young adult patients that present with hip pain has been outlined. Such an approach is required to adequately and reliably recognise the features that can be present in cases at the milder end of the spectrum in relation to structural abnormalities and will assist the diagnostic and decision-making process in this patient group. Further imaging modalities are usually essential in further assessing the young adult hip and can be utilised to confirm a suspected diagnosis and contribute to the appropriate management plan. 
Author contributions Popat R, Lee S and George DA wrote the paper; Amiras D and Sarraf K supervised the paper; all authors read and approved the final manuscript.

Funding This research did not receive any specific grant from funding agencies in the public, commercial, or not-for-profit sectors.

\section{Compliance with ethical standards}

\section{Conflict of interest None.}

Open Access This article is licensed under a Creative Commons Attribution 4.0 International License, which permits use, sharing, adaptation, distribution and reproduction in any medium or format, as long as you give appropriate credit to the original author(s) and the source, provide a link to the Creative Commons licence, and indicate if changes were made. The images or other third party material in this article are included in the article's Creative Commons licence, unless indicated otherwise in a credit line to the material. If material is not included in the article's Creative Commons licence and your intended use is not permitted by statutory regulation or exceeds the permitted use, you will need to obtain permission directly from the copyright holder. To view a copy of this licence, visit http://creativecommons.org/licenses/by/4.0/.

\section{References}

1. Parker S, Nagra NS, Kulkarni K, Pegrum J, Barry S, Hughes R et al (2017) Inadequate pelvic radiographs: Implications of not getting it right the first time. Ann R Coll Surg Engl. https://doi.org/10.1308/ resann.2017.0095

2. Tannast M, Siebenrock KA, Anderson SE (2007) Femoroacetabular impingement: radiographic diagnosis - What the radiologist should know. Am J Roentgenol 188:1540-1552. https://doi.org/10.2214/ AJR.06.0921

3. Clohisy JC, Carlisle JC, Beaulé PE, Kim YJ, Trousdale RT, Sierra $\mathrm{RJ}$ et al (2008) A systematic approach to the plain radiographic evaluation of the young adult hip. J Bone Jt Surg Ser A 90:47-66. https://doi.org/10.2106/JBJS.H.00756

4. Kay RM, Jaki KA, Skaggs DL (2000) The effect of femoral rotation on the projected femoral neck-shaft angle. J Pediatr Orthop 20:736-739. https://doi.org/10.1097/00004694-200011000-00007

5. Ching W, Robinson J, Mcentee M (2014) Patient-based radiographic exposure factor selection: a systematic review. J Med Radiat Sci 61:176-190. https://doi.org/10.1002/jmrs.66

6. Lampignano JP, Kendrick LE (2018) Bontragers textbook of radiographic positioning and related anatomy. Elsevier, Amsterdam

7. Laage H, Barnett JC, Brady JM, Dulligan PJJ, Fett HCJ, Gallagher TF et al (1953) Horizontal lateral roentgenography of the hip in children; a preliminary report. J Bone Jt Surg Am 35(A):387-398

8. Akiho S, Yamamoto T, Kinoshita K, Matsunaga A, Ishii S, Ishimatsu $\mathrm{T}$ (2017) The utility of false-profile radiographs for the detection of osteoarthritis progression in Acetabular dysplasia. JBJS Open Access.

9. Clohisy JC, Nunley RM, Otto RJ, Schoenecker PL (2007) The frog-leg lateral radiograph accurately visualized hip cam impingement abnormalities. Clin Orthop Relat Res. https://doi.org/10.1097/ BLO.0b013e3180f60b53

10. Dunn DM, Notley B (1952) Anteversion of the neck of the femur; a method of measurement. J Bone Jt Surg Br 34(B):181-186. https:// doi.org/10.1001/archotol.1952.00710010477010

11. Jerre R, Billing L, Hansson G, Karlsson J, Wallin J (1996) Bilaterality in slipped capital femoral epiphysis: importance of a reliable radiographic method. J Pediatr Orthop B 5:80-84
12. Jerre R, Billing L, Hansson G, Wallin J (1994) The contralateral hip in patients primarily treated for unilateral slipped upper femoral epiphysis. Long-term follow-up of 61 hips. J Bone Jt Surg Br 76:563-567

13. Sharp I (1961) Acetabular dysplasia the acetabular angle. J Bone Jt Surg Br 43(B):268-272. https://doi.org/10.1017/CBO9781107 415324.004

14. Butler P, Mitchell AWM, Ellis H (2015) Applied radiological anatomy. Cambridge University Press, Cambridge. https://doi. org/10.1017/CBO9780511663406

15. Bowerman JW, Sena JM, Chang R (1982) The teardrop shadow of the pelvis; anatomy and clinical significance. Radiology 143:659662. https://doi.org/10.1148/radiology.143.3.7079492

16. Manaster BJ (1996) From the RSNA refresher courses. Total hip arthroplasty: radiographic evaluation. RadioGraphics 16:645-660. https://doi.org/10.1148/radiographics.16.3.8897629

17. Delaunay S, Dussault RG, Kaplan PA, Alford BA (1997) Radiographic measurements of dysplastic adult hips. Skeletal Radiol 26:75-81. https://doi.org/10.1007/s002560050197

18. Tönnis D (1976) Normal values of the hip joint for the evaluation of X-rays in children and adults. Clin Orthop Relat Res 119:39-47. https://doi.org/10.1097/00003086-197609000-00007

19. Mast JW, Brunner RL, Zebrack J (2004) Recognizing acetabular version in the radiographic presentation of hip dysplasia. Clin Orthop Relat Res 418:48-53

20. Ogata S, Moriya H, Tsuchiya K, Akita T, Kamegaya M, Someya M (1990) The journal of bone and joint surgery acetabular cover in congenital dislocation of the hip. J Bone Jt Surf Br. https://doi. org/10.1053/j.jvca.2012.11.024

21. Ömeroglu H, Biçimoglu A, Aguş H, Tümer Y (2002) Measurement of center-edge angle in developmental dysplasia of the hip: A comparison of two methods in patients under 20 years of age. Skeletal Radiol. https://doi.org/10.1007/s002560100402

22. Jesse MK, Petersen B, Strickland C, Mei-Dan O (2013) Normal anatomy and imaging of the hip: emphasis on impingement assessment. Semin Musculoskelet Radiol. https://doi.org/10.1055/s-0033-1348090

23. Apley AG, Wientroub S (1981) The sagging rope sign in Perthes' disease and allied disorders. J Bone Jt Surg Br 63(B):43-7. https:// doi.org/10.1302/0301-620X.63B1.7204473

24. Cuomo AV, Fedorak GT, Moseley CF (2015) A practical approach to determining the center of the femoral head in subluxated and dislocated hips. J Pediatr Orthop 35:556-560. https://doi.org/10.1097/ BPO.0000000000000281

25. Beltran LS, Rosenberg ZS, Mayo JD, De Tuesta MD, Martin O, Neto LP et al (2013) Imaging evaluation of developmental hip dysplasia in the young adult. Am J Roentgenol 200:1077-1088. https ://doi.org/10.2214/AJR.12.9360

26. Lunn DE, Lampropoulos A, Stewart TD (2016) Basic biomechanics of the hip. Orthop Trauma 30:239-246. https://doi.org/10.1016/j. mporth.2016.04.014

27. Ogata K, Goldsand EM (1979) A simple biplanar method of measuring femoral anteversion and neck-shaft angle. J Bone Jt Surg Am 61:846-851

28. Toogood PA, Skalak A, Cooperman DR (2008) Proximal femoral anatomy in the normal human population. Clin Orthop Relat Res 467:876. https://doi.org/10.1007/s11999-008-0473-3

29. Gulan G, Matovinović D, Nemec B, Rubinić D, Ravlić-Gulan J (2000) Femoral neck anteversion: values, development, measurement, common problems. Coll Antropol 24:521-527

30. Dastane M, Dorr LD, Tarwala R, Wan Z (2011) Hip offset in total hip arthroplasty: Quantitative measurement with navigation. Clin Orthop Relat Res 469:429-436. https://doi.org/10.1007/s1199 9-010-1554-7

31. Ito K, Minka M-A, Leunig M, Werlen S, Ganz R (2001) Femoroacetabular impingement and the cam-effect. J Bone Jt Surg Br 83(B):171-6. https://doi.org/10.1302/0301-620X.83B2.0830171 
32. Peelle MW, Della Rocca GJ, Maloney WJ, Curry MC, Clohisy JC (2005) Acetabular and femoral radiographic abnormalities associated with labral tears. Clin Orthop Relat Res. https://doi. org/10.1097/01.blo.0000181147.86058.74

33. Barton C, Salineros MJ, Rakhra KS, Beaulé PE (2011) Validity of the alpha angle measurement on plain radiographs in the evaluation of cam-type femoroacetabular impingement. Clin Orthop Relat Res 469:464-469. https://doi.org/10.1007/s11999-010-1624-x
34. Jones DHA (2010) Shenton's line. J Bone Jt Surg Br 92(B):1312-5. https://doi.org/10.1302/0301-620X.92B9.25094

Publisher's Note Springer Nature remains neutral with regard to jurisdictional claims in published maps and institutional affiliations. 